\title{
EL SECTOR INFORMAL URBANO DEL ECUADOR: UNA VISIÓN DE SU MAGNITUD ACTUAL Y LA PARTICULAR SITUACIÓN DE LA MUJER EN ÉSTE*
}

\author{
Carlos Gonzales Cevallos**:
}

\section{INTRODUCCIÓN}

El trabajo informal es sin lugar a dudas uno de los fenómenos sociales y económicos de mayor importancia en América Latina, pero de manera muy especial con ciertas estructuras socio-económicas como el Ecuador.

No es nada difícil encontrarse en ciertos sectores de las ciudades más importantes del Ecuador, un ejército de vendedores que ofrecen las mercaderías y los servicios más variados; desde un humilde lustrabotas que deja el calzado reluciente por 15 ctvs. de dólar hasta adinerados comerciantes de artículos electrónicos que ofrecen cd-players o calculadoras de 20,50 o más dólares, pasando por vendedores de ropa de niños, cosméticos, ropa interior o, sastres que reparan prendas de vestir en plena acera así como, improvisados "chefs" que preparan "mini parrilladas" denominados "pinchos" con 50 gramos de carne, 100 gramos de ciertos embutidos, una patata pequeña y un cierto tipo banano, atravesados por un palillo similar a los que se utiliza para la comida china.

El fenómeno de la informalidad es bastante complejo, tanto en su génesis como en su situación actual, pero sin lugar a dudas guarda una estrecha relación con el desempleo y sobretodo con el subempleo, razón por la cual en el presente trabajo se tratará de presentar una visión concreta de la magnitud actual del Sector Informal Urbano (SIU) del Ecuador, partiendo de los niveles de desempleo y subempleo registrados en los últimos años. Para una mejor comprensión de la situación descrita, se realizará primero una breve revisión teórica sobre la conceptualización del Sector Informal y de la microempresa, con sus principales características.

Finalmente, se realizará una descripción más detallada y específica sobre la situación de la mujer en el Sector Informal, porque la particular realidad socio-económica de las mujeres ecuatorianas, especialmente de aquellas que tienen bajos ingresos, da origen también,a una caracterización especial de la forma cómo ellas se han articulado al mencionado Sector.

\section{EL SECTOR INFORMAL Y LA MICROEMPRESA: UNA BREVE REVISIÓN CONCEPTUAL}

Hernando de Soto uno de los primeros estudiosos de este Sector señala que, los inmigrantes fueron conformando el Sector Informal en las ciudades del Perú, especialmente en Lima, "para vivir, comerciar, manufacturar, transportar y hasta consumir, ... utilizando medios ilegales para obtener fines legales" (De Soto, 1987, pág. 36).

Este concepto, basado en la relación de quienes componen el Sector Informal, con la estructura jurídica de la sociedad, permitiría definirlo como el conjunto de actores económicos, que "utilizan medios ilegales para obtener fines legales".

Otro estudioso del tema, Jaime Mezzerra, toma como base para su definición, las características económicas y productivas de este Sector, describiéndolo como:

"Un conjunto heterogéneo de actividades productivas cuyo principal elemento común es emplear a un número de personas que no podrían ocuparse en el Sector Moderno', y debe subemplearse con relativamente escaso acceso a factores de producción complementarios al trabajo" (Mezzerra, 1987, pág 54).

Otro concepto importante, señalado por José Luis Ortiz, define al Sector Informal como:

"Un gran Sector Poblacional, cuya fuerza de trabajo no es absorbida por las formas modernas de producción y debe realizar actividades que le permitan autogenerar ingresos, en una lógica de subsistencia antes que de acumulación” (Ortiz, 1987, pág 106).

Tratando de sintetizar y mejorar estos conceptos, se podría señalar que el Sector Informal es: El conjunto de agentes económicos que no pueden ocuparse en el Sector

Esta investigación es parte de una investigación académica desarrollada en la Pontifica Universidad Católica del Ecuador.

$*$ Economista. Asesor de la II Vicepresidencia del Congreso Nacional del Ecuador.

1. De la economía 
Moderno de la economía; debiendo realizar actividades que les permitan autogenerar ingresos, bajo la restricción de un escaso acceso a factores de producción complementarios al trabajo, debiendo utilizar para esto con cierta frecuencia, medios ilegales para obtener fines legales.

Los miembros del Sector Informal desarrollan sus actividades económicas a través de entes denominados comúnmente microempresas, aunque muchas de ellas no tienen ninguna estructura administrativa o funcional que tenga alguna relación con lo que normalmente se concibe como empresa. Sobre éstas Miguel Ángel Cartiglia, ha enunciado una definición basada en sus principales características. Según este autor, las microempresas son:

Las unidades económicas que operan con una relación capital trabajo, una disponibilidad tecnológica y un productividad física inferiores a los mínimos que rigen para las actividades correspondientes del Sector formal; cuya factibilidad económica depende en gran medida de la utilización de una fuerza de trabajo cuyo costo promedio es menor al que se paga en idénticas actividades en las empresas formales, $\mathrm{y}$ que desarrollan su actividad en mercados en los cuales existe cierta libertad de ingresos, en función de la escala y los procedimientos productivos" (Cartiglia, 1978, pág. 124).

Sin embargo, una definición más concisa de microempresa podría ser: La unidad económica en la cual, uno o varios agentes económicos pertenecientes al Sector Informal desarrollan actividades económicas que les permiten autogenerar ingresos.

Para una mejor concepción de lo que es la microempresa resulta conveniente hacer una descripción de sus principales cualidades. El sector microempresarial se caracteriza por:

1. Escaso o nulo acceso al capital y consecuentemente, una baja relación capital / trabajo,

2. Trabajo con tecnologías primarias,

3. Acceso al crédito en forma escasa y costosa,

4. Incipiente organización técnica y administrativa del negocio,

5. Frecuente utilización en cantidades significativas de mano de obra familiar no remunerada,

6. Operación fuera del marco legal (total o parcialmente),

7. Salarios generalmente inferiores a los vigentes para trabajos análogos del Sector Formal.

8. Escasa División Social del Trabajo en las unidades de producción.

9. Reducida incorporación del progreso técnico, a las áreas de administración y producción y,

10. Escasa o nula diferenciación entre el trabajo de dirección supervisión y producción propiamente dicha ${ }^{2}$.

Otro factor muy importante a considerarse en la microempresa es la "Lógica de Subsistencia” señalada por Ortiz. Esta Lógica implica que, el objetivo perseguido por los microempresarios con sus actividades económicas es la supervivencia personal y familiar, constituyéndose en la motivación que está presente en todas sus decisiones para trabajar, crear y crecer. Esta "Lógica de Supervivencia surge de las condiciones de vida y está latente en cada acto económico". (Alarcón, 1989, pág. 34).

Sin embargo, la incidencia de la "Lógica de Supervivencia" no es algo que permanece por siempre en la mente del microempresario ya que seguiría desapareciendo conforme su empresa entre a un proceso de crecimiento permanente y sostenido, porque esto hará que dicha Lógica sea reemplazada por la típica lógica de acumulación.

\section{SUBEMPLEO Y SECTOR INFORMAL: SU VIN- CULACIÓN CON LA CRISIS ECONÓMICA Y PRINCIPALES CARACTERÍSTICAS DE SU SITUA- CIÓN ACTUAL}

El desempleo y el subempleo, pero de manera particular el segundo, han sido, son y serán (al menos en el mediano plazo) dos de los problemas socio-económicos de mayor impacto, complejo tratamiento y difícil solución que tiene el Ecuador. Unas pocas cifras pueden ayudar a visualizar el porqué de esta afirmación.

Según el Instituto Ecuatoriano de Estadística y Censos, INEC, la Tasa de Desempleo Bruta ${ }^{3}$ creció del 7.1\% en 1994 al $9.2 \%$ en 1997, mientras que la Tasa de Subempleo Bruta bajó del 45.2\% en 1994 al 40.4\% en 1997 (INEC, 1994 pág. 6/ 1997 pág. 6). Posteriormente, la poca estabilidad política y económica que ha debido enfrentar por el país desde la destitución del Presidente Bucaram en 1997 y muy particularmente, la crisis vivida por el país en el primer semestre de 1999, habría provocado un incremento alarmante de estas cifras, haciendo que el desempleo abierto se ubique en el $18 \%$ y el subempleo en el $55 \%$, según CEDATOS, una de las empresas de mayor trayectoria y prestigio en investigaciones sociales y de opinión pública del País ${ }^{4}$.

Sin embargo, el tener un nivel de subempleo tan alto no es nada nuevo en el Ecuador ya que, a finales de los años ochenta, cuando el País afrontaba ya las severas consecuencias de tener una "Década Perdida" (como la mayoría de países de América Latina), éste fenómeno afectaba ya al 44.5\% de la Población Económicamente Activa en 1987 y al 48\% de la misma, en 1989. (CONADE / CFN / IIEPUCE, 1990, pág. 30).

Como se puede notar en las cifras expuestas, de los dos problemas descritos, aquel que tiene mayor importancia, tanto por el porcentaje de la población que comprende como por la variedad de formas en las cuales se presenta, según se describió al inicio del presente trabajo, así como por las dificultades para su estudio, es el subempleo, puesto que la "subocupación se expresa en distintas formas y puede variar

2. Características mencionadas en su mayor parte por: Placencia, 1987, pág. 309

3. Esta tasa está definida por el INEC como:

Número de desocupados / Población Económicamente Activa

Mientras tanto, la Tasa de Subempleo Bruta es igual a:

La suma de: la Tasa de Subempleo en el Sector Moderno más el porcentaje de la PEA total que está en el Sector Informal Urbano.

4. Cifras expuestas por el Director de la Institución en el Seminario "Análisis de la Realidad Nacional: pasado, presente y futuro del Ecuador", el 31 de Agosto de 1999. 
ostensiblemente según los indicadores y variables que se utilicen para medirla” (Íbid, pág. 30).

Este problema tiene orígenes que van mucho más allá del estancamiento y recesión económica (aunque estos factores tienen una incidencia muy importante sobre él), ya que, a pesar de las elevadas tasas de crecimiento de la economía nacional logradas por la bonanza petrolera en los años setenta (hasta el $12 \%$ anual), "el subempleo siempre se mantuvo en niveles relativamente altos. Así, del $30 \%$ registrado en 1968 bajó solamente al 24 \% en 1975” (Íbid), aunque este fue uno de los mejores años que vivió el Ecuador durante la bonanza del denominado "Oro negro" 5 .

Si bien, en base a la clasificación realizada por el INEC, existe también subempleo en el Sector Moderno de la economía, la mayor parte de la población que se encuentra en esta situación laboral se halla en el Sector Informal de la economía, razón por la cual existe una estrecha relación entre la magnitud del subempleo y la magnitud de este Sector. Así, de los valores registrados para la Tasa de Subempleo Bruta, en 1994 y 1997, sólo corresponden a la Tasa de Subempleo en el Sector Moderno el $5.6 \%$ y $4.1 \%$, respectivamente. El resto de subempleados estaban ubicados en el Sector Informal.

El concepto de desempleo tiene relación directa con el de Sector Informal y microempresa, porque a través de su trabajo en las microempresas que forman parte de él, los subempleados enfrentan su problema de ingresos y a la vez, generan un circuito de oferta-demanda que satisface la mayor parte de las necesidades de consumo que tienen los sectores de bajos ingresos.

En la mayoría de actividades económicas del Ecuador, se puede identificar la presencia de microempresas que desarrollan la más variada producción de bienes y servicios. Sin embargo, como se podrá observar en el Cuadro No. 1, que se presenta a continuación, en 1997 la mayor parte de los miembros del Sector Informal Urbano se dedican al comercio, artesanía y confección, ya que el $48.5 \%$ de ellos se ubica en la categoría ocupacional "Comerciantes y Vendedores" y el $29.12 \%$ se ubica en la categoría "Artesanos e industria textil”, quedando el $22.38 \%$ restante, repartidos en el resto de categorías ocupacionales. Estas cifras indicarían el por qué se produce muchas veces, una analogía entre Sector Informal y Comercio Informal.

Cuadro No. 1 TIPOS DE OCUPACIÓN DE LOS MIEMBROS DE SIU

\begin{tabular}{|l|r|}
\hline TIPO DE OCUPACION & \% de Participación \\
\hline & en el SIU \\
\hline Profesionales y técnicos & $0.05 \%$ \\
\hline Personal Directivo & $1.10 \%$ \\
\hline Personal administrativo & $1.56 \%$ \\
\hline Comerciantes y Vendedores & $48.50 \%$ \\
\hline Medios de Transporte & $7.71 \%$ \\
\hline Artesanos e ind. textil & $29.12 \%$ \\
\hline Artes Gráficas & $2.99 \%$ \\
\hline Trab. en estriba y almacenes & $1.28 \%$ \\
\hline Servicios personales & $7.68 \%$ \\
\hline TOTAL DEL SIU & $100.00 \%$ \\
\hline
\end{tabular}

FUENTE: INEC, "Encuesta Anual de Empleo, Subempleo”, Quito, 1997, pág. 20. ELABORACIÓN: EI autor.
Sobre estas cifras es importante señalar que los tipos de ocupaciones no reflejan la gran variedad y diversidad de actividades que desarrollan los microempresarios, especialmente aquellos situados en el comercio y la manofactura. Así, en el comercio se contarían entre los principales rubros que son objeto de transacción, los siguientes:

a. Artículos de primera necesidad: vestido, calzado, alimentos, de la más variada calidad, presentación, precio o tecnología (desde zapatos Nike y dulces Nestlé hasta blue jeans $100 \%$ ecuatorianos y productos de cosecha reciente como tomates arvejas o bananos),

b. Pequeños electrodomésticos,

c. Artículos de papelería y bazar,

d. Muebles y enseres para el hogar (vasos, cucharas, cuchillos),

e. Cosméticos y otros artículos de uso personal,

f. Medicinas, tradicionales y de casas farmacéuticas.

Mientras tanto, en la manufactura y los servicios se tendría como rubros principales:

a. Confección y reparación de prendas de vestir,

b. Confección y reparación de calzado,

c. Confección y reparación de artículos de cuero como carteras, maletas, bolsas,

c. Fabricación de adornos personales,

d. Fabricación de pequeñas herramientas y otros trabajos de cerrajería,

e. Fabricación y reparación de artículos de madera, a nivel artesanal.

\section{LAS PARTICULAR SITUACIÓN DE LA MUJER DEL SECTOR INFORMAL URBANO}

Además de las características comunes a todo el Sector Informal Urbano, que se han descrito en el presente trabajo, en sociedades como la ecuatoriana, la división del trabajo por género asigna el liderazgo de la producción al varón, mientras que a la actividad productiva de la mujer se le asigna un papel marginal, subsidiario. La necesidad de articular permanentemente su rol como madres y esposas, con el de productoras o comerciantes, da lugar a que muchos actores sociales (entre los que se encuentran también algunas de las mismas mujeres trabajadoras) no perciban este trabajo productivo como tal, sino como parte de sus labores domésticas.

"Entre las mujeres (de los sectores populares) es más frecuente la actividad laboral a tiempo parcial, esporádica, estacional, con tareas difíciles de distinguir de las domésticas, en empresas familiares, sin remuneración, o por cuenta propia. En las áreas rurales y, de manera particular en el sector agropecuario, las dificultades anotadas se vuelven mucho más fuertes, debido al carácter estacional de la producción agrícola” (CONADE / CFN / IIE-PUCE, 1990, pág. 47).

5. Apelativo que se le dio en ciertos círculos de la sociedad ecuatoriana al petróleo durante los años que este producto mantuvo sus mejo res precios. 
Esta situación hace que, la participación de la mujer en el Sector Informal sea mayor de lo que pueden mostrar las estadísticas, porque es muy probable que al momento de realizar los estudios muestrales estas mujeres hayan aparecido como desempleadas o como parte de la población económicamente inactiva, aunque también realicen labores económicamente productivas con cierta regularidad. Sin embargo, como se puede observar a continuación, las estadísticas dan cuenta de una participación muy importante de la mujer en el mencionado Sector.

Según los datos presentados en la "Encuesta Permanente de Hogares, Empleo, Subempleo, Desempleo”, en 1994 las mujeres representan el 39.08\% de la PEA ocupada en el Sector Informal Urbano y, de este universo, el $32.54 \%$ constaban como jefas de hogar. Aunque 1997, estos porcentajes habían disminuido al $30.05 \%$ y el $31.75 \%$ respectivamente, las cifras dan muestras claras de la significativa participación de la mujer en el Sector Informal Urbano y más aún, de la importancia de estas mujeres trabajadoras en la manutención de sus hogares. Lamentablemente, no se dispone de información a cerca del Sector Informal Rural, pero se puede asumir que, en la mayor parte del país, la participación de la mujer campesina en el mercado laboral informal y en la jefatura de los hogares es más alta que la registrada en el Sector Urbano, porque "la agricultura campesina de minifundio, en muchas comunidades del altiplano ecuatoriano ha quedado bajo la responsabilidad principal de las mujeres, con el soporte complementario de los niños" (CONADE, CFN, IIE-PUCE, 1990, pág. 48)

Las actividad del Sector Informal en la cual tienen mayor participación las mujeres es el comercio minorista, siguiéndole en importancia, la producción manofacturera y los servicios.

Por otra parte, el porcentaje de mujeres es considerablemente mayor en las unidades informales que cuentan con un menor número de trabajadores ya que, el $67 \%$ de los trabajadores ubicados en las unidades productivas unipersonales está constituido por fuerza laboral femenina, mientras que sólo un 25\% de la mano de obra femenina está en lugares que cuentan con 3 a 5 trabajadores (CONADE / CFN / IIE-PUCE, 1990, pág. 49)

La sub-estimación del trabajo de la mujer perteneciente al Sector Informal (aunque este fenómeno existe también en el Sector Formal del Ecuador y muchos países), se refleja en la desigualdad de ingresos que ellas tienen respecto de los varones que desarrollan sus actividades en este mismo Sector ya que, como se muestra en el Cuadro No. 2, las mujeres tienen una participación mayoritaria en los segmentos de menores ingreso, mientras que existe una participación totalmente minoritaria en los segmentos de mayores ingresos.

La situación que se vive en la Costa, la región mayor población urbana y mayor SIU del país, refleja una concentración aún mayor de las mujeres pertenecientes a dicho Sector en los niveles de más bajos ingresos ya que, el 78\% de mujeres se ubica en el rango más bajo y sólo un $17 \%$ en el rango más alto. (Maguiña, 1996, pág. 7). También es importante señalar que, el $71 \%$ de los familiares no remunerados que laboran en las unidades económicas del SIU está constituido por mujeres.
Cuadro No. 2 INGRESO DE LOS INTEGRANTES DEL SIU, POR SEXO Región Sierra

\begin{tabular}{|l|r|r|r|r|}
\hline TRAMO DE INGRESO & Personas & \multirow{2}{*}{$\%$ del SIU } & \multicolumn{2}{|c|}{ Distribución por Sexo } \\
\cline { 3 - 5 } & & & Hombres & Mujeres \\
\hline Menos de 100,000 & 14,368 & $3.00 \%$ & $38.00 \%$ & $62.00 \%$ \\
100,000 a 199,000 & 32,771 & $6.80 \%$ & $36.20 \%$ & $63.80 \%$ \\
200,000 a 299,000 & 49,975 & $10.40 \%$ & $37.10 \%$ & $62.90 \%$ \\
300,000 a 399,000 & 48,607 & $10.10 \%$ & $48.80 \%$ & $51.20 \%$ \\
400,000 a 499,000 & 46,361 & $9.60 \%$ & $67.20 \%$ & $32.80 \%$ \\
500,000 a 599,000 & 35,476 & $7.40 \%$ & $56.50 \%$ & $43.50 \%$ \\
600,000 o más & 146,221 & $30.30 \%$ & $69.50 \%$ & $30.50 \%$ \\
Familiar no & 80,479 & $16.70 \%$ & $28.60 \%$ & $71.40 \%$ \\
remunerado & & & & \\
Otros & 27,700 & $5.70 \%$ & $54.90 \%$ & $45.10 \%$ \\
\hline
\end{tabular}

FUENTE: Jorge Maguiña, "Referencia Estadistica acerca del SIU en el Ecuador"

1996, pág. 5.

ELABORACIÓN : 日 autor

\section{CONCLUSIONES}

- El desempleo y el subempleo, pero de manera particular el segundo, han sido, son y serán (al menos en el mediano plazo) dos de los problemas socio-económicos de mayor impacto, complejo tratamiento y difícil solución que tiene el Ecuador, aunque especial importancia tendría el segundo por la cantidad de población afectada y la complejidad de su estructuración y desarrollo.

- Aunque también existe también subempleo en el Sector Moderno de la economía, la mayor parte de la población que se encuentra en esta situación se halla en el Sector Informal de la economía razón por la cual, la evolución del mismo tiene un gran peso en la economía global del país, pero de manera especial en la economía de la población con menores ingresos.

- La proporción de la PEA que se encuentra en subempleo y en el Sector Informal, depende en buena parte de la recesión y estancamiento económico del país, pero depende también de otros factores, muy posiblemente de tipo estructural, porque también ha existido importantes niveles de subempleo en años de bonanza económica.

- El trabajo de la mujer perteneciente al Sector Informal se encuentra sub- dimencionado y sub-valorado, aunque dicha inequidad existe también en el Sector Formal del Ecuador y muchos países. Sin embargo, este problema se vuelve significativamente más grave en el Sector Informal, porque en muchos casos, las actividades productivas que éstas desarrollan se toman como parte de sus obligaciones domésticas y familiares, todo lo cual se traduce en una significativa concentración de las mujeres, en los niveles más bajos de ingreso que se registran dentro del Sector Informal, mientras que con los hombres de este mismo Sector; se registra la situación inversa. 


\section{BIBLIOGRAFÍA}

Alarcón, César, Sector Informal: Problema o Solución?, Quito, Fondo Ecuatoriano de Desarrollo, 1989.

CARTiglia, Miguel Angel, "La Empresa Informal”, en El Sector Informal Urbano en los Países Andinos, Carbonetto, Mezzerra y otros, 2da. ed., Quito, ILDISCEPESIU, 1987.

CONADE, CFN, PUCE, Informalidad Urbana, Quito, CONADE, CFN, PUCE, 1992.

CORFEC, tríptico promocional, Quito, 1997.
De Soto, Hernando, El Otro Sendero, Bogotá, Oveja Negra, 1987.

INEC, Encuesta Anual de Empleo, Subempleo, Desempleo, Quito, INEC, 1994, 1997.

Maguiña, Jorge, Referencia estadística a cerca del SIU en el Ecuador, (Documento de Desarrollo Institucional), CEPESIU, Quito, 1998.

MezzerRa, Jaime, "Microempresa, Presente y Futuro", en El Sector Informal Urbano en los Países Andinos, Carbonetto, Mezzerra y otros, 2da. ed., Quito, ILDISCEPESIU, 1987.

\section{RESUMEN}

El desempleo y el subempleo, pero de manera particular el segundo, han sido, son y serán (al menos en el mediano plazo) dos de los problemas socio-económicos de mayor impacto, complejo tratamiento y difícil solución que tiene el Ecuador y otros países con similar estructura socio-económica. Aunque el subempleo (conocido también como Sector Informal), llega a sus niveles más altos (medido a través del porcentaje de la PEA que está inmersa en él), en los tiempos de estancamiento e inestabilidad económica su configuración y evolución depende también, en una proporción significativa, de factores estructurales.

Palabras clave: Sector informal, desempleo, subempleo, mujeres, Ecuador.

\section{ABSTRACT}

The unemployment and the underemployment, spetially the second one, are among the problems of the ecuadorian society, that have the highest impact in the population, complex treatment and complicated solution. Although the underemployment, called too "Informal Sector" of the economy, gets its highest levels (measured by the percentaje of the "Econonically Active Population" wich is underemployed), in the years when the country has have recession and economic instability, its configuration and evolution depends on structural motivations, in an important proportion.

Key Words: Informal Sector, unemployment, underemployment, womens, Ecuador. 


\section{Entrecaminos}

An Interdisciplinary Joumal of Latin American Affairs

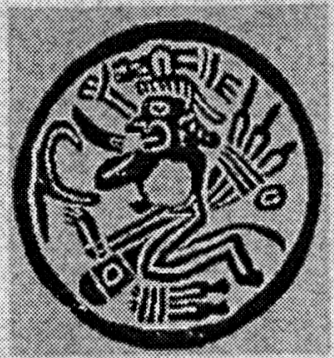

Spring 1999, Volume 4

Featuring:

Reflexiones sobre la democracia en América Latina

And

EI desafío de la democracia en América Latina

By Dr. Arturo Valenzuela

Special Assistant to the President and Senior Director for

Inter-American Affairs, United States National Security Council

The United States and Colombia: An Uneasy Relationship By Michael Shifter

Senior Fellow at the Inter-American Dialogue

The Role of Uruguay in the Southern Cone:

Integration, Education and Strategic Opportunity

By Eric Roland

Fulbright Scholar

Peregrinación, memoria y subjetividad: las nuevas identidades urbanas en tiempos de globalización

By Myriam A. Zapata Jiménez

Universidad Pedagógica Nacional de Colombia

A Publication of the Georgetown University Center for Latin American Studies Edmund A. Walsh School of Foreign Service 